\title{
On the Design of Transferred Electron Oscillators and Amplifiers
}

\author{
Hammershaimb, E.; Jeppesen, Palle; Jeppsson, B; Jondrup, P; Kallback, B; Schjær-Jacobsen, Hans
}

Published in:

3rd European Microwave Conference

Link to article, DOI:

10.1109/EUMA.1973.331623

Publication date:

1973

Document Version

Publisher's PDF, also known as Version of record

Link back to DTU Orbit

Citation (APA):

Hammershaimb, E., Jeppesen, P., Jeppsson, B., Jondrup, P., Kallback, B., \& Schjær-Jacobsen, H. (1973). On the Design of Transferred Electron Oscillators and Amplifiers. In 3rd European Microwave Conference (Vol. Volume 1, pp. 1-5). IEEE. https://doi.org/10.1109/EUMA.1973.331623

\section{General rights}

Copyright and moral rights for the publications made accessible in the public portal are retained by the authors and/or other copyright owners and it is a condition of accessing publications that users recognise and abide by the legal requirements associated with these rights.

- Users may download and print one copy of any publication from the public portal for the purpose of private study or research.

- You may not further distribute the material or use it for any profit-making activity or commercial gain

- You may freely distribute the URL identifying the publication in the public portal 
E. Hammershaimb, P. Jeppesen, B. Jeppsson," P. J $\not$ ndrup, B. Källbäck*

H. Schjaer-Jacobsen

Laboratory of Electromagnetic Theory

Technical University of Denmark

Lyngby

Denmark

'Microwave Institute Foundation
Stockholm
Sweden

\section{Introduction}

GaAs transferred electron devices can be operated both as oscillators and stable, reflection-type, amplifiers. A most important feature of the supercritically doped stable device is the very large gain-bandwidth product potentially available. Therefore section 2 of this paper presents a computer aided optimization procedure for the design of amplifiers in order to fully utilize the wideband properties of the device. It is of importance also for the construction of oscillators, both single frequency and tunable, to be able to establish simple design criterions. In section 3 it is shown that there exists a gradual transition from the small signal properties of the stable device to the large signal behaviou $r$ of the oscillator and that therefore it is a fruitful approach to treat $C W$ transferred electron oscillator from the amplifier point of view rather than as the conventional travelling high-field domain device. Thus useful oscillator design criterions can be derived from the easily evaluated properties of the stable device.

\section{Amplifier design}

In this section a computer aided design of a multiple slug coaxial transferred electron amplifier is presented. The strength of the method stems from the fact that it is based directly on the measured small signal impedance of the packaged device and on an accurate model of the microwave circuit. Thus the design does not involve any assumptions of the device impedance. Instead the measured small signal impedance is used directly in a nonlinear optimization procedure, in which the calculated minimum gain in the prescribed frequency range is maximized while the resulting ripple is kept under control.

A multiple slug $50 \Omega$ coaxial circuit is used serving the double purpose of providing both reactive response shaping and real impedance transformation between the load and the diode. Loss in the coaxial transmission line as well as step susceptances are included in the computer model of the circuit.

The stable GaAs device is mounted at the end of a $50 \Omega$ coaxial line and characterized by the measured small signal device impedance, $Z_{d}$. Fig. 1 shows a typical example of the frequency dependent $Z_{d}=R_{d}+j X_{d}$ measured on a Hewlett Packard automatic network analyzer. Fig. 1 also shows the corresponding chip impedance, $Z_{c}$, for the unpackaged device. 
A Nyquist stability analysis shows that the unpackaged device is both open circuit stable (OCS) and short circuit stable (SCS). For a driving source impedance, $R_{g}$, it will thus remain stable for any $R_{g}$. The packaged device however is OCS but SCU and therefore it will remain stable for $R_{g}>-R_{d}\left(f_{x}\right)$ but become unstable for $R_{g}<-R_{d}\left(f_{x}\right)$. This is the reason why the packaged device is stable in a $50 \Omega$ matched transmission line When the packaged device is tuned by a circuit impedance, $Z_{L}=R_{L}+j X_{L}$, stability can be ensured by keeping $R_{L}>-$ $-\mathrm{R}_{\mathrm{d}}$, min irrespective of $\mathrm{X}_{\mathrm{L}}$.

For the sake of brevity the theoretical optimization and the corresponding experimental verification is restricted to an illustrative example based on the packaged device impedance $\mathrm{Z}_{\mathrm{d}}$ in Fig. 1. The theoretical and experimental gain-frequency response for this example is shown in Fig. 2. A coaxial circuit with three slugs was used here giving a voltage gain- $3 \mathrm{db}$ bandwidth product of $6.5 \mathrm{GHz}$.

\section{Oscillator design}

It has been found that GaAs devices normally used in CW oscillators also easily can be stabilized and used as amplifiers. It is suggested here that $C W$ transferred electron oscillators often operate in a mode that can be characterized from an amplifier point of view rather than from the conventional approach assuming travelling high-field domains. For these cases, that of course exclude highly non-sinusoidal voltage excitations, useful design criterions for oscillator construction can be established from the easily obtained properties of the stable devices. Thus also bias voltage and temperature effects can be included. Evidence for the gradual transition from the small signal properties of the stable device to the large signal behaviour of the oscillating device is given below.

Typical measured small-signal admittances for stable GaAs $n^{+} \mathrm{nn}^{+}$-devices are shown in Figs. 3 and 4 . The diodes are doped to approximately $1.210^{15}$ $\mathrm{cm}^{-3}$, have low-field resistances around $10 \mathrm{ohms}$ and the rmal resistances around $100^{\circ} \mathrm{C} / \mathrm{W}$ The admittances given in these figures are chip admittances. The microwave package has been modelled by an optimization and modelling procedure described at this conference (1)

Figs. 3 and 4 show that for increasing bias voltage and temperature the negative conductance curve moves towards lower frequencies. For this type of device very wide-band amplifier or oscillator operation can the refore be accomplished over a broad temperature range by means of voltage compensation.

Diodes of the type above have been operated as oscillators in a coaxial slug circuit. For a fixed circuit Fig. 5 shows the operating frequency and output power as a function of bias voltage The diode oscillates at $11.327 \mathrm{GHz}$ with an output power of $9.0 \mathrm{~mW}$ for a bias voltage of 7.5 volts and at $11.200 \mathrm{GHz}$ with $20 \mathrm{~mW}$ at 9 volts. The impedance $Z_{L}$ (f) of the circuit, measured after removing the diode, is plotted from 11.0 to $11.4 \mathrm{GHz}$ in the Smith chart in Fig. 5. The stable device impedance, $\mathrm{Z}_{d}\left(\mathrm{I}_{1}\right)$ as a function of $\mathrm{RF}$-drive was then measured in a $50 \Omega$ circuit at $11200 \mathrm{GHz}$ for a bias of 9 volts and at 11.327 for 7.5 volts. The resulting curves for $-Z_{d}\left(I_{1}\right)$ are also shown in the Smith chart. As expected the crossover point between $Z_{L}(f)$ and $-Z_{d}\left(I_{1}\right)$ occurs for a higher RF-drive level for the highest power operation at $11.200 \mathrm{GHz}$. For this frequency and the bias voltage of 9 volts the device impedance is shown in more 
detail in Fig. 6 along with the added power, both as a function of RF-drive. The circuit impedance $Z_{L}=R_{L}+j X_{L}=(3.5+j 5.8) \Omega$ and the oscillator output power of $20 \mathrm{~mW}$ have been indicated. Excellent agreement is obtained and the small difference in measured oscillator power and added power is probably caused by losses in the oscillator circuit.

The experiment presented above demonstrates that accurate and detailed design criterions for $\mathrm{CW}$ transferred electron oscillators can be derived from an analysis of the stable device impedance and its dependence on RF-drive, bias voltage and temperature. For a great number of applications however only a measurement of the small signal properties provides the necessary information for the oscillator design.

\section{$\underline{\text { Reference }}$}

(1) Altmäe, M. "Interactive microwave circuit design program package for minicomputers", Proc. 1973 European Microwave Conf. This issue, Brussels Sept. 4-7, 1973.
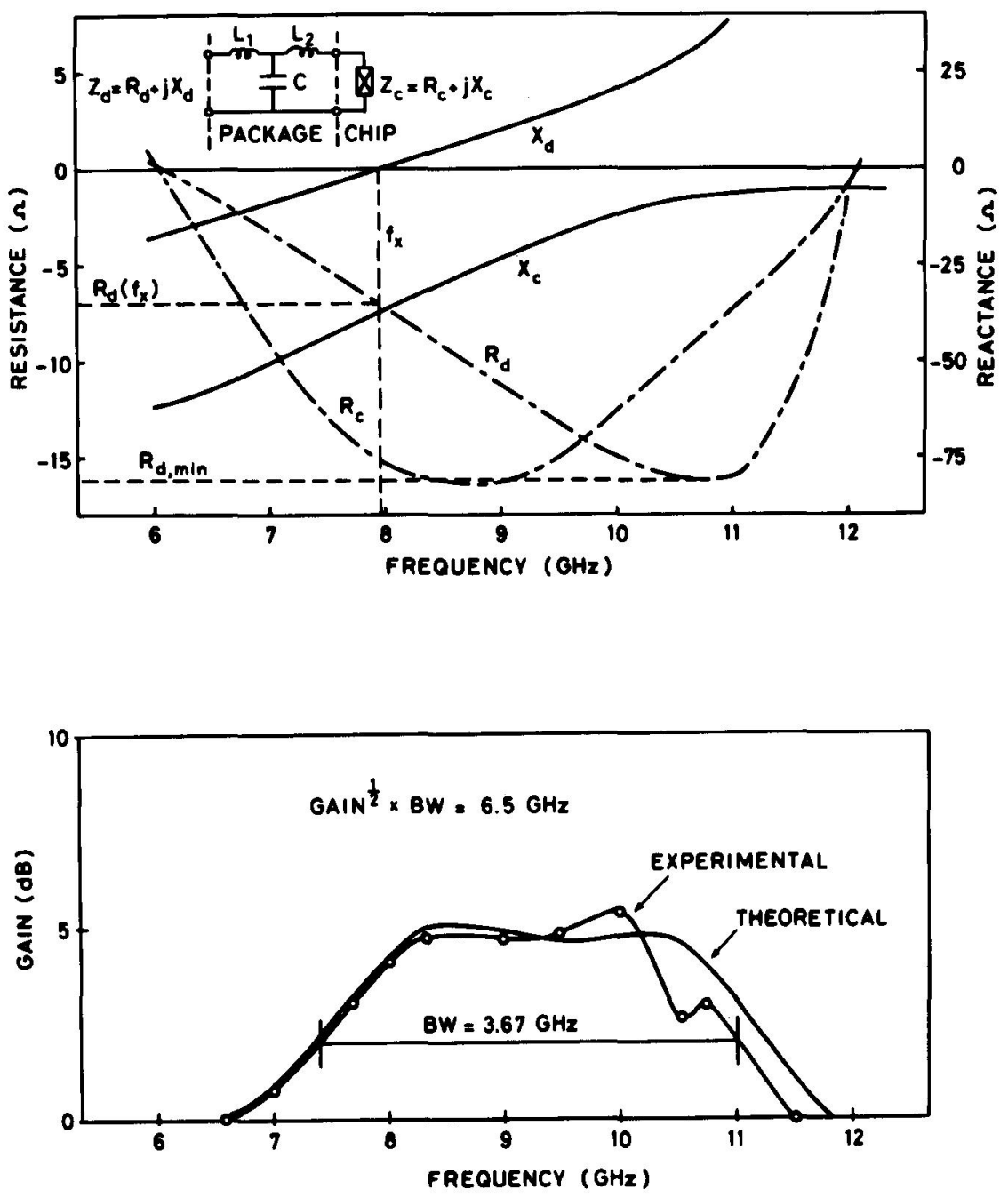

Fig. 1

Typical measured impedance for packaged $\left(z_{d}=R_{d}+j x_{d}\right)$ and unpackaged $\left(z_{c}=R_{c}+j X_{c}\right)$ TED. Device data: $\mathrm{n}_{\mathrm{o}}=$ $1.5 \times 10^{15} \mathrm{~cm}^{-3}$, $I=12 \mu \mathrm{m}, R_{0}=5.6 \Omega$, $\mathrm{V}_{0}=7.8 \mathrm{~V}$. Package data: $L_{1}=0.325 \mathrm{nH}, L_{2}=0.300$ $\mathrm{nH}$ and $\mathrm{C}=0.385 \mathrm{pF}$.

Fig. 2

Experimental and theoretical gain-frequency response of a three-slug amplifier for packaged device impedance $z_{d}$ of Fig. 1. 

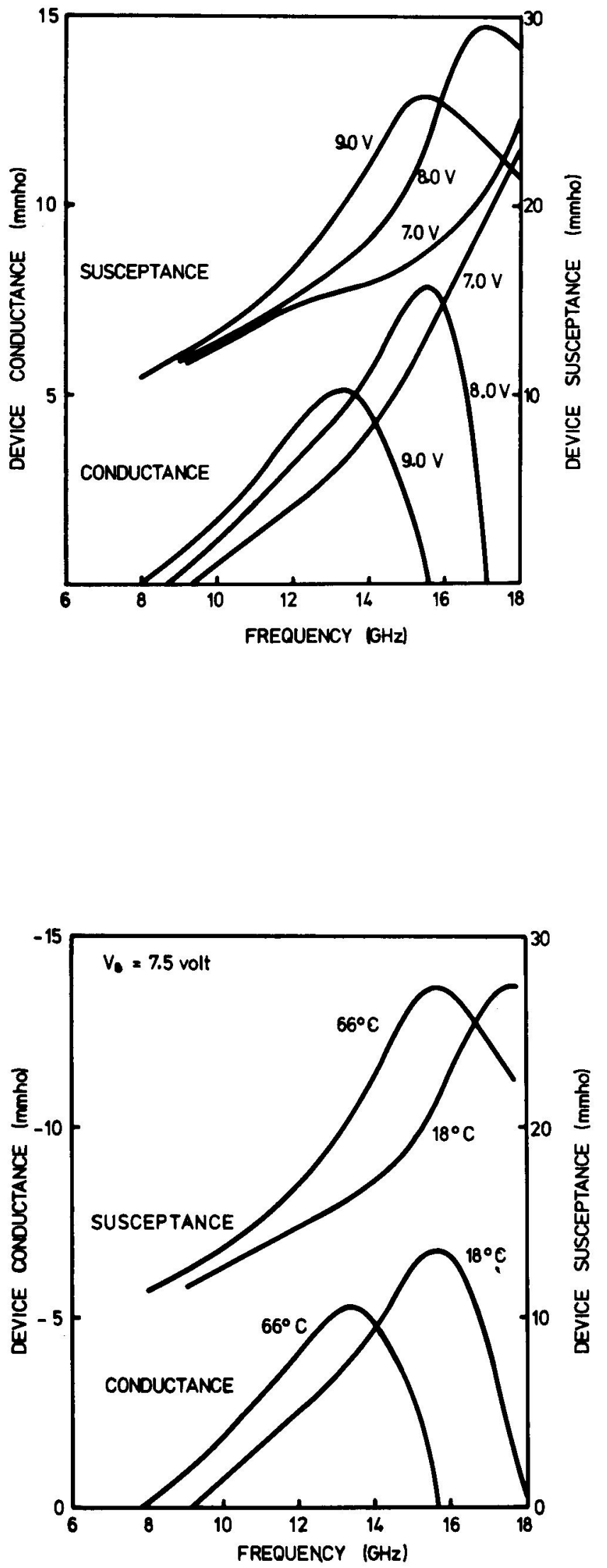

Fig. 3

Typical measured frequency and bias dependence for small-signal chip admittance for stable GaAs $\mathrm{n}^{+} \mathrm{nn}^{+}-$device. Device data: $n_{0}=1.2 \times 10^{15}$ $\mathrm{cm}^{-3}, \mathrm{~L}=10 \mu \mathrm{m}, \mathrm{R}_{0}=10 \Omega$, thermal resistance $100^{\circ} \mathrm{C} / \mathrm{W}$.

\section{Fig. 4}

Typical measured frequency and temperature dependence for small-signal chip admittance for device in Fig. 3. 


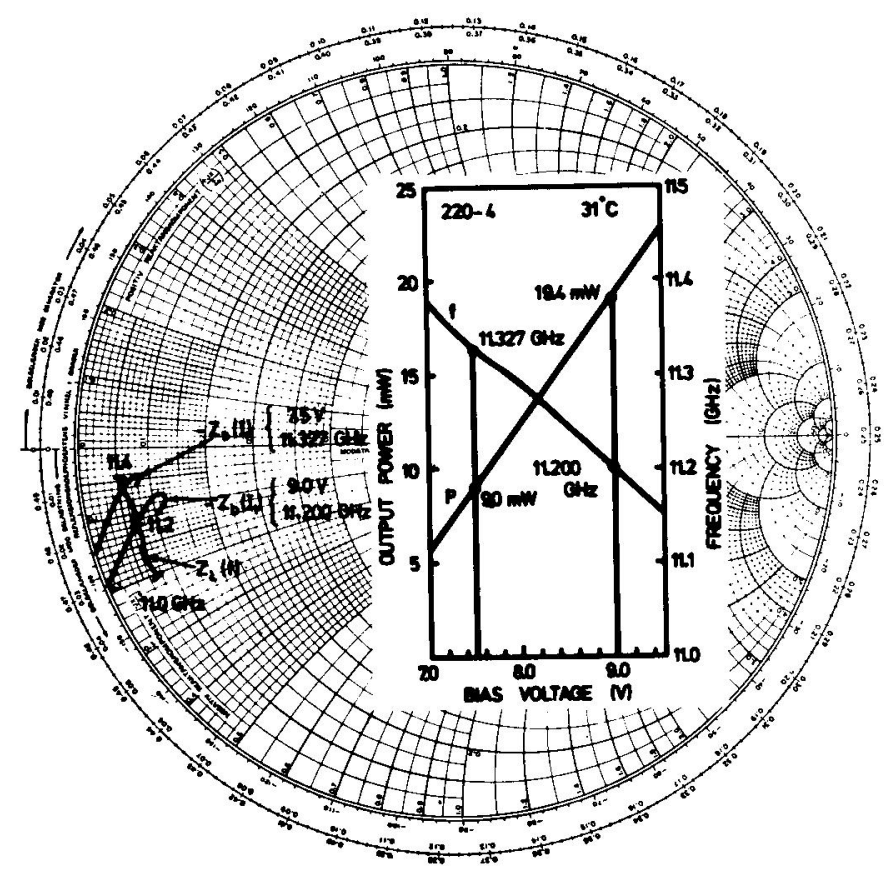

Fig. 5 Oscillator output power and frequency versus bias voltage for device in Fig. 3 mounted in fixed coaxial circuit. Also shown are corresponding coaxial circuit impedance $z_{L}$ from 11.0 to $11.4 \mathrm{GHz}$ and negative device impedance $-Z_{D}$ vs. increasing drive level for two sets of bias voltage and frequency.

a)

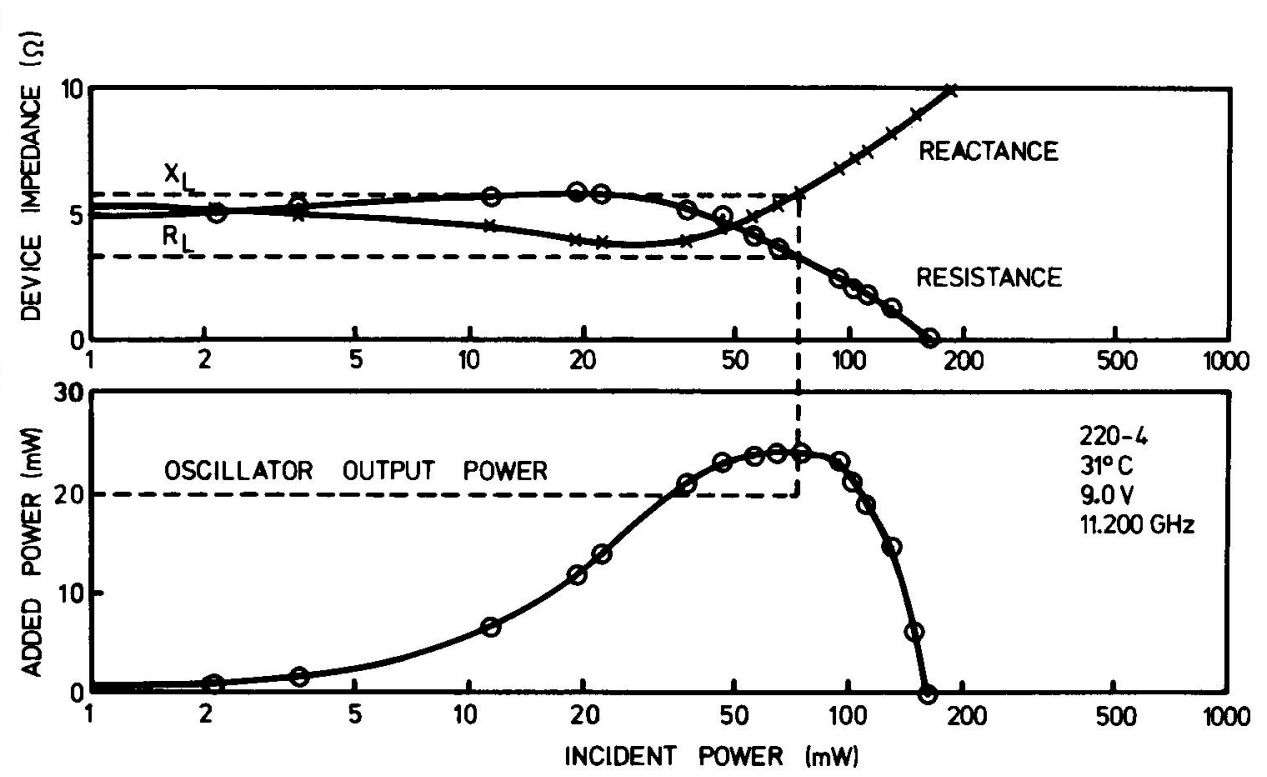

Fig. 6 (a) Negative resistance and reactance vs. incident power for one of the device impedances in Fig. 5. (b) Corresponding added power. 